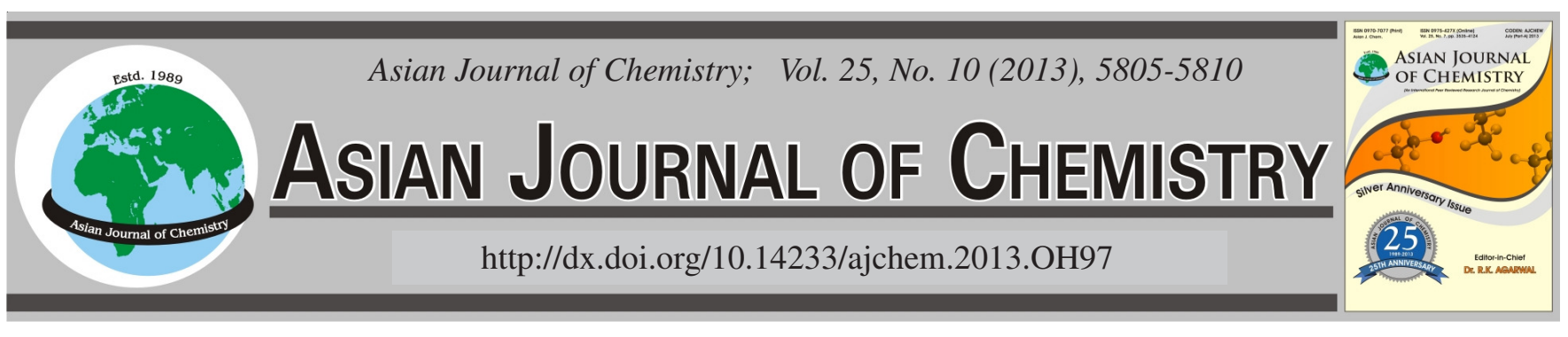

\title{
Performance of C,N-Impregnated Photocatalyst Coupled with Continuous- Flow Reactor for Removal of Gaseous Aromatic Pollutants $\dagger$
}

\author{
WAN-KUEN JO* and HYUn-JUNG KANG
}

Department of Environmental Engineering, Kyungpook National University, 80 University Road, Bukgu, Daegu 702-701, Republic of Korea

*Corresponding author: Fax: +82 53 9506579; Tel: +82 53 9506584; E-mail: wkjo@knu.ac.kr

AJC-13340

\begin{abstract}
Previous activity tests of carbon and nitrogen co-impregnated photocatalysts $\left(\mathrm{C}\right.$ and $\mathrm{N}$-impregnated-TiO $\left.{ }_{2}\right)$ for environmental pollution controls were primarily performed in the aqueous phase to investigate the decomposition of water pollutants. This study examined the photocatalytic activities of $\mathrm{C}, \mathrm{N}-\mathrm{TiO}_{2}$ photocatalysts for the purification of indoor-level gaseous organic compounds under different experimental conditions. The as-prepared $\mathrm{C}, \mathrm{N}-\mathrm{TiO}_{2}$ and unmodified $\mathrm{TiO}_{2}$ powders were characterized using XRD, SEM, diffuse reflectance UV-VIS-NIR spectra and Fourier transform infrared spectra. The $\mathrm{C}, \mathrm{N}-\mathrm{TiO}_{2}$ powders exhibited a shift in the absorbance spectrum towards the visible light region when compared to $\mathrm{TiO}_{2}$ powders, indicating that the as-prepared $\mathrm{C}, \mathrm{N}-\mathrm{TiO}_{2}$ photocatalyst could be effectively activated by visible-light irradiation. The surface characteristics of the two types of photocatalysts differed. Additionally, the average photocatalytic degradation efficiencies for benzene, toluene, ethyl benzene and xylene (BTEX) obtained from the $\mathrm{C}, \mathrm{N}-\mathrm{TiO}_{2}$ system were 27, 81, 95 and $99 \%$, respectively, whereas those of the $\mathrm{TiO}_{2}$ powders were close to zero, 19, 47 and $56 \%$, respectively. Under the experimental conditions used in this study, the photocatalytic degradation efficiencies for BTEX were higher for the photocatalytic system with the fluorescent lamp than for that with light-emitting diodes.
\end{abstract}

Key Words: Degradation efficiency, Operational condition, Aromatic pollutant, Light-emitting diode.

\section{INTRODUCTION}

Nonmetallic nitrogen (N)- or carbon (C)-impregnated $\mathrm{TiO}_{2}$ nanophotocatalysts have been found to have superior photocatalytic activity under visible-light irradiation due to effective narrowing of the energy band gap of $\mathrm{TiO}_{2}{ }^{1,2}$. The shift in the absorption band toward the visible-light region for $\mathrm{N}$-impregnated $\mathrm{TiO}_{2}$ can be attributed to the $\mathrm{N}$-induced midgap energy (N 2p) state, which was formed slightly above the top of the valence band $(\mathrm{O} 2 \mathrm{p})^{3}$ or narrowing of the band gap by mixing the $\mathrm{N} 2 \mathrm{p}$ and $\mathrm{O} 2 \mathrm{p}$ states in the valence band $\mathrm{d}^{4}$. The carbon dopant has been described as a substitutional anion associated with the -4 oxidation state in the Ti-C bond in carbide, or as an interstitial cation associated with the +4 oxidation state in the $\mathrm{C}-\mathrm{O}$ bond in carbonates ${ }^{5}$. These oxidation states are attributed to the band gap narrowing of $\mathrm{TiO}_{2}$ or the formation of a localized mod-gap state, thereby extending the absorbance of $\mathrm{C}-\mathrm{TiO}_{2}$ into visible light ${ }^{6}$. C-TiO 2 also reduces the electron-hole recombination which in practice reduces the effectiveness of $\mathrm{TiO}_{2}$ as a photocatalyst ${ }^{7}$.

More recently, co-impregnation of $\mathrm{TiO}_{2}$ with carbon and nitrogen $\left(\mathrm{C}, \mathrm{N}-\mathrm{TiO}_{2}\right)$ has been suggested as an alternative technique to effectively extend the absorbance into visible light with a higher photocatalytic activity over single element doping into $\mathrm{TiO}_{2}{ }^{8,9}$. This was ascribed to a synergistic effect of co-impregnation with the two elements in which the impregnated $\mathrm{C}$ atoms would increase adsorption of chemicals and the impregnated $\mathrm{N}$ atoms would enhance the visible-light absorption. A number of researchers have synthesized $\mathrm{C}, \mathrm{N}-\mathrm{TiO}_{2}$ photocatalysts using various routes such as solvothermal ${ }^{10}$, mechanochemical ${ }^{11}$, hydrolysis-polymerization-calcination ${ }^{12}$, hydrothermal $^{9}$ and sol-gel processes ${ }^{13}$ and found that as-prepared $\mathrm{C}, \mathrm{N}-\mathrm{TiO}_{2}$ photocatalysts exhibited high photocatalytic activities under visible-light irradiation. For these studies, the photocatalytic activity tests were carried out in the aqueous phase to examine the decomposition of water pollutants, such as phenol and methylene blue, or inorganic gas (nitrogen monoxide). However, it is worth noting that both photon absorbance kinetics and reaction kinetics of environmental pollutants differ at the liquid-solid and gas-solid interfaces ${ }^{14}$. This difference prompts assessment of the photocatalytic activities of as-prepared $\mathrm{C}, \mathrm{N}-\mathrm{TiO}_{2}$ photocatalysts for the removal of gas-phase pollutants.

This study investigated the photocatalytic activities of $\mathrm{C}, \mathrm{N}-\mathrm{TiO}_{2}$ photocatalysts for the purification of indoor-level

$†$ Presented to the 6th China-Korea International Conference on Multi-functional Materials and Application, 22-24 November 2012, Daejeon, Korea 
gaseous organic compounds under different experimental conditions. The photocatalysts were prepared using a versatile solvothermal synthetic method. In addition, the photocatalytic activities of commercially-available Degussa P-25 $\mathrm{TiO}_{2}$ powders were compared with those determined for the as-prepared $\mathrm{C}, \mathrm{N}-\mathrm{TiO}_{2}$ powders. The target compounds included benzene, toluene, ethyl benzene and xylene (BTEX), which are commonly detected at high concentrations in indoor and outdoor environments ${ }^{15}$. Moreover, these compounds are toxic or potentially toxic to humans ${ }^{16}$.

\section{EXPERIMENTAL}

Synthesis and characterization of $\mathrm{C}, \mathrm{N}-\mathrm{TiO}_{2}$ photocatalysts: The $\mathrm{C}, \mathrm{N}-\mathrm{TiO}_{2}$ photocatalysts were prepared using a solvothermal method. For this method, titanium isopropoxide (TTIP, $4.8 \mathrm{~mL}$ ) was added to $68 \mathrm{~mL}$ of isopropanol. This solution was mixed with $4 \mathrm{~mL}$ of $\mathrm{HNO}_{3}(0.5 \mathrm{M})$ and $0.78 \mathrm{~g}$ of hexamethylenetetramine (HMT) and then stirred for $1 \mathrm{~h}$ at room temperature to obtain a gel-type photocatalyst. Subsequently, the gel-type photocatalyst was transferred into a 100 $\mathrm{mL}$ Teflon-lined stainless steel autoclave and then heated at $120{ }^{\circ} \mathrm{C}$ for $4 \mathrm{~h}$. After thermal treatment was completed the autoclave was cooled and then kept at room temperature for 20 h. The resulting $\mathrm{C}, \mathrm{N}-\mathrm{TiO}_{2}$ photocatalysts were dried at $90{ }^{\circ} \mathrm{C}$ for $24 \mathrm{~h}$ and then calcined at $300{ }^{\circ} \mathrm{C}$ for $4 \mathrm{~h}$.

The as-prepared $\mathrm{C}, \mathrm{N}-\mathrm{TiO}_{2}$ and un-impregnated $\mathrm{TiO}_{2}$ powders were characterized using X-ray diffraction, scanning emission microscope, diffuse reflectance UV-VIS-NIR analysis and Fourier transform infrared (FTIR) analysis. XRD patterns were determined on a Rigaku D/max-2500 diffractometer with $\mathrm{CuK}_{\alpha}$ radiation operated at $40 \mathrm{kV}$ and $100 \mathrm{~mA}$ in the range of $20-80$ o $(2 \theta)$ at a scanning rate of $10^{\circ} \mathrm{min}^{-1}$. The particle morphology was observed using a Hitachi S-4300 and EDX$350 \mathrm{FE}-\mathrm{SEM}$ at an acceleration voltage of $15 \mathrm{kV}$. Visible absorption spectra were obtained for the dry pressed disk samples using a Varian CARY 5G spectrophotometer equipped with an integrating sphere. Polytetrafluoroethylene was used as a reference. FTIR analysis was performed on a PerkinElmer Spectrum GX spectrophotometer at a resolution of $4 \mathrm{~cm}^{-1}$ in the spectral range of $4000-400 \mathrm{~cm}^{-1}$, using a $\mathrm{KBr}$ pellet for sample preparation.

Photocatalytic activity test: The photocatalytic activity of the prepared $\mathrm{C}, \mathrm{N}-\mathrm{TiO}_{2}$ and unmodified $\mathrm{TiO}_{2}$ photocatalysts was examined using an annular-type Pyrex reactor with a dimension of $5.2 \mathrm{~cm}$ inside diameter and $26 \mathrm{~cm}$ length. The as-prepared $\mathrm{C}, \mathrm{N}-\mathrm{TiO}_{2}$ or unmodified $\mathrm{TiO}_{2}$ powders were coated onto the inner surface of the Pyrex reactor. Air leakage from the reactor was determined by measuring the flow rate at the reactor outlet and comparing this with the supply airflow rate. Visible radiation was supplied using a conventional visible-light lamp or visible light-emitting diodes and its intensity was measured using a digital Lux Meter (INS Model DX-100). The reactor outside was wrapped with aluminum foil to minimize the transmission loss of light from the reactor lamp through the Pyrex tube, as well as for the transmission gain of light from laboratory fluorescent lamps. This reactor allows for a uniform light distribution onto the surfaces of the photocatalysts. In addition, the reactor was designed to direct the flow of incoming air toward the UV light to increase air turbulence inside the reactor, thereby enhancing distribution of the target compounds onto the photocatalyst surface. The standard gas, which was prepared by injecting standard gases into a mixing chamber via a syringe pump (model 210, KdScientific Inc.), flowed above the $\mathrm{C}, \mathrm{N}-\mathrm{TiO}_{2}$-coated Pyrex. The humidity was adjusted by passing zero-grade air through a charcoal filter, followed by a humidifying device in a water bath. SFR was controlled using rotameters calibrated against a dry test meter. The RH values were measured immediately adjacent to the photocatalytic reactor inlet using a humidity meter (Thermo Recorder TR-72S, T \& D Co.)

This study investigated the effect of light sources on the destruction efficiency of BTEX. Visible radiation was supplied by an 8-W fluorescent daylight lamp (F8T5DL, Youngwha Lamp Co.) or blue light-emitting diodes with a peak light intensity at $470 \mathrm{~nm}$. Other parameters were fixed to their representative values, which were as follows: lamp, 8-W fluorescent daylight lamp; RH, 45 \%; IC, 0.1 ppm; SFR, 0.5 L min-1. The representative hydraulic diameter (HD is defined as the inside diameter of the annular reactor tube minus the outside diameter of the lamp) of the photocatalytic reactor was 35 $\mathrm{mm}$. The visible radiation intensity was measured as $2.1 \mathrm{~mW}$ $\mathrm{cm}^{-2}$ at a distance from the visible-light lamp equal to half the $\mathrm{HD}$ of the reactor. The weight of the $\mathrm{C}, \mathrm{N}$-impregnated $\mathrm{TiO}_{2}$ and un-impregnated $\mathrm{TiO}_{2}$ film coated inside the reactor were 3.4 and $3.5 \mathrm{mg} \mathrm{cm}^{-2}$, respectively.

Sampling and analysis: Gas samples were collected at both the inlet and outlet using an empty Tedlar bag at a constant flow rate for 10 min every hour. Gas from the sampling bag was then drawn through a adsorbent trap containing $0.2 \mathrm{~g}$ of Tenax TA using a constant flow-sampling pump (Aircheck Sampler Model 224-PCXR8, SKC). All sampling was conducted at ambient temperature. The target species collected on the adsorbent trap were analyzed by coupling a thermal desorption system (SPIS TD, Donam Inc.) to a gas chromatograph (Agilent 7890A) equipped with a flame ionization detector. The peak areas with respect to other compounds on the GC chromatogram were not significantly high and the could not be easily assigned to theoretically expected intermediates; thus, they were not quantified.

The quality assurance and quality control program for measurements of gaseous target compounds included laboratory blank traps and spiked samples. At the beginning of the day, a laboratory blank trap was analyzed to check for any trap contamination. However, none was observed. An external standard was also analyzed daily to check the quantitative response. When the quantitative response differed by more than $10 \%$ from that predicted by the specified calibration equation, a new calibration equation was determined. The method detection limits ranged from 1.5 to $5.2 \mu \mathrm{g} \mathrm{m}^{-3}$, depending on the target volatile organic compounds.

\section{RESULTS AND DISCUSSION}

Characteristics of $\mathrm{C}, \mathrm{N}-\mathrm{TiO}_{2}$ and un-impregnated $\mathrm{TiO}_{2}$ photocatalysts: The prepared $\mathrm{C}, \mathrm{N}-\mathrm{TiO}_{2}$ powders and the $\mathrm{TiO}_{2}$ Degussa P25 powders were characterized by XRD, SEM, UVvisible spectroscopy and FTIR analysis. Fig. 1 exhibits the 
XRD patterns of $\mathrm{C}, \mathrm{N}-\mathrm{TiO}_{2}$ and unmodified $\mathrm{TiO}_{2}$ Degussa $\mathrm{P} 25$. The XRD results of unmodified titania exhibited an anatase phase of $\mathrm{TiO}_{2}$ with a major peak at $25.2^{\circ} 2 \theta$ and a rutile phase with a distinct peak at $27.4^{\circ} 2 \theta$. These findings are similar to those of previous studies ${ }^{17,18}$. However, $\mathrm{C}, \mathrm{N}-\mathrm{TiO}_{2}$ did not reveal any distinct rutile crystal phase peak at $27.42 \theta$, although it still showed a distinct anatase crystal phase peak at $25.2^{\circ}$ 20. Moreover, unlike the unmodified $\mathrm{TiO}_{2}$ no distinct anatase peaks were observed for the $\mathrm{C}, \mathrm{N}-\mathrm{TiO}_{2}$. These findings are consistent with those of previous studies ${ }^{9,10,12,13}$. The differences in $\mathrm{XRD}$ patterns between unmodified $\mathrm{TiO}_{2}$ and $\mathrm{C}, \mathrm{N}-\mathrm{TiO}_{2}$ were ascribed to the calcination temperature of $\mathrm{C}, \mathrm{N}-\mathrm{TiO}_{2}$ and the role of $\mathrm{C}$ and $\mathrm{N}$ elements for $\mathrm{C}, \mathrm{N}-\mathrm{TiO}_{2}$. Previous studies ${ }^{10,12,13}$ showed that crystallinity transformations from rutile $\mathrm{TiO}_{2}$ to anatase $\mathrm{TiO}_{2}$ occur during calcination processes and that these transformations increase as calcination temperature increases. The presence of $\mathrm{C}$ and $\mathrm{N}$ elements for $\mathrm{C}, \mathrm{N}-\mathrm{TiO}_{2}$ could also influence the phase transformation ${ }^{12}$.

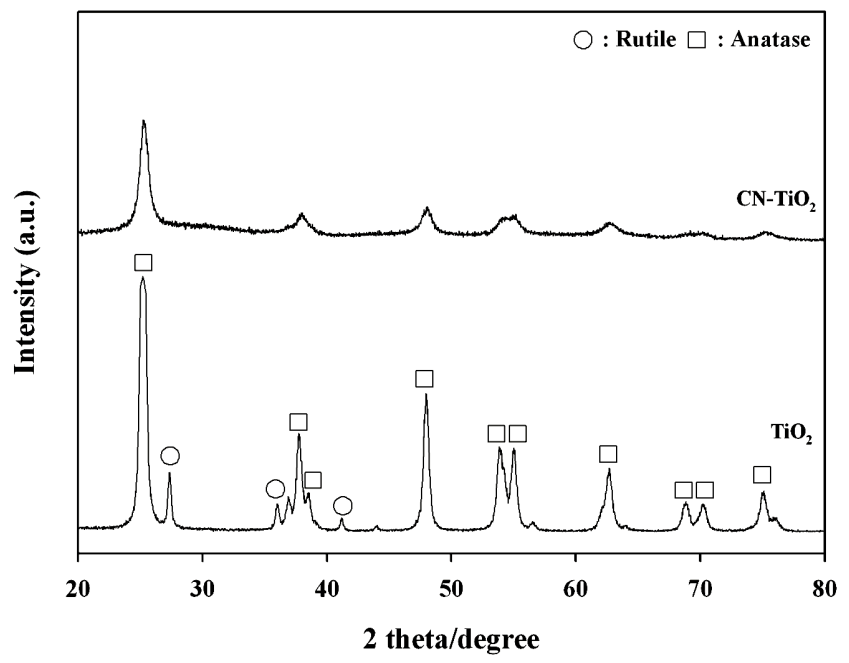

Fig. 1. X-ray diffraction spectra of $\mathrm{C}, \mathrm{N}-\mathrm{TiO}_{2}$ and $\mathrm{TiO}_{2}$ powders

The SEM images of both $\mathrm{C}, \mathrm{N}-\mathrm{TiO}_{2}$ and unmodified $\mathrm{TiO}_{2}$ Degussa P25 are presented in Fig. 2. Lower agglomeration was observed for the $\mathrm{C}, \mathrm{N}-\mathrm{TiO}_{2}$ than for the unmodified sample. The average sizes of the agglomerate for $\mathrm{C}, \mathrm{N}-\mathrm{TiO}_{2}$ and unmodified $\mathrm{TiO}_{2}$ were $c a$. 10 and $20 \mathrm{~nm}$, respectively, which are consistent with the results reported by Wang and $\mathrm{Lim}^{10}$. The larger size of $\mathrm{C}, \mathrm{N}-\mathrm{TiO}_{2}$ when compared to the unmodified $\mathrm{TiO}_{2}$, is supported by Wang and $\mathrm{Lim}^{10}$, who reported that the crystallite size increased as the crystallinity transformation from rutile $\mathrm{TiO}_{2}$ to anatase $\mathrm{TiO}_{2}$ occurred. Additionally, the $\mathrm{C}, \mathrm{N}-\mathrm{TiO}_{2}$ showed more aggregation of particles when compared to unmodified $\mathrm{TiO}_{2}$. These findings are attributed to the sintering reaction among small particles for the $\mathrm{C}, \mathrm{N}-\mathrm{TiO}_{2}{ }^{19}$. However, it should be noted that the particle size of $\mathrm{C}, \mathrm{N}-\mathrm{TiO}_{2}$ photocatalysts can vary with calcination temperature ${ }^{12,13}$.

The UV-visible absorbance spectra of the two photocatalysts are presented in Fig. 3. The $\mathrm{P} 25 \mathrm{TiO}_{2}$ revealed an absorption edge at $\lambda \approx 410 \mathrm{~nm}$, which was consistent with that reported by other researchers ${ }^{17,20,21}$. The light absorbance intensity in the UV region $(<400 \mathrm{~nm})$ was higher for unmodified $\mathrm{TiO}_{2}$ than for $\mathrm{C}, \mathrm{N}-\mathrm{TiO}_{2}$. However, unlike the unmodified $\mathrm{TiO}_{2}$, the $\mathrm{C}, \mathrm{N}-\mathrm{TiO}_{2}$ powders showed a shift of the absorbance spectrum towards the visible light region $(400-800 \mathrm{~nm})$. Similarly, previous studies ${ }^{9,13,22}$ reported that the $\mathrm{C}, \mathrm{N}-\mathrm{TiO}_{2}$ prepared using other synthetic routes (sol-gel, magnetron sputtering and hydrothermal methods) showed a light absorbance shift to the visible light region, although their absorbance intensities differed. Taken together, these findings indicate that the C,N$\mathrm{TiO}_{2}$ powders prepared in this study could be effectively activated by visible-light irradiation.
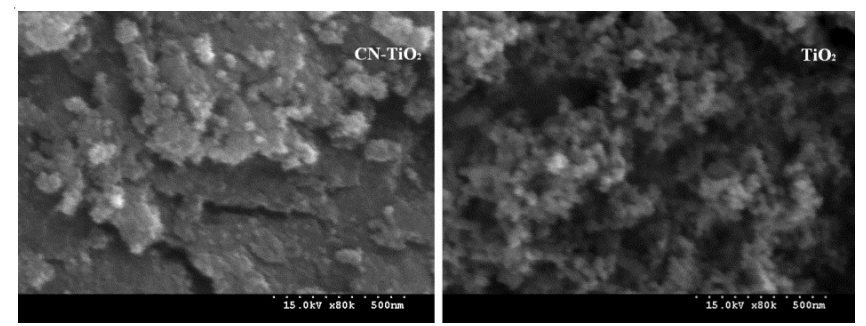

Fig. 2. Scanning electron microscope pattern of $\mathrm{C}, \mathrm{N}-\mathrm{TiO}_{2}$ and $\mathrm{TiO}_{2}$ powders

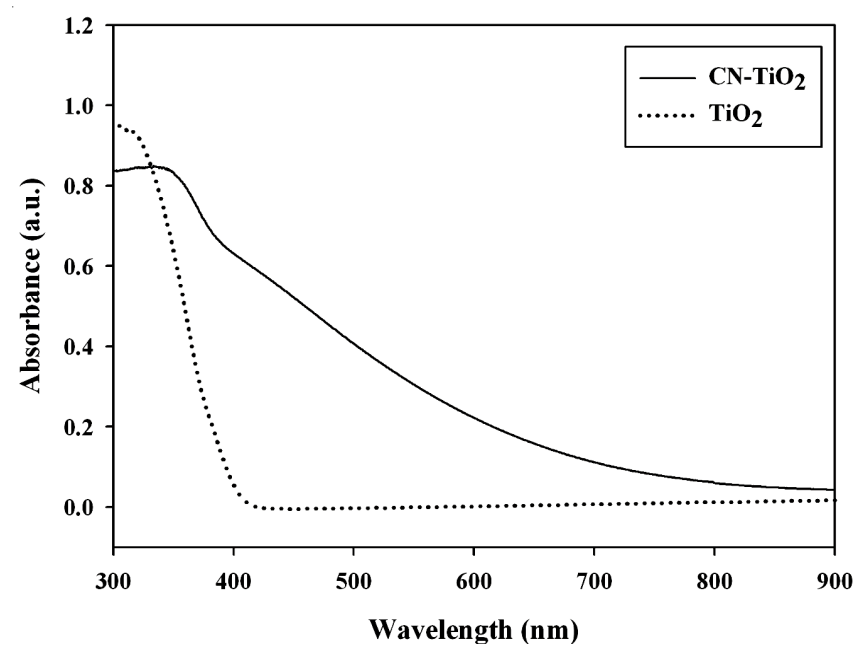

Fig. 3. UV-visible absorption spectra of $\mathrm{C}, \mathrm{N}-\mathrm{TiO}_{2}$ and $\mathrm{TiO}_{2}$ powders

Fig. 4 shows the FTIR spectra of the prepared $\mathrm{C}, \mathrm{N}-\mathrm{TiO}_{2}$ and unmodified $\mathrm{TiO}_{2}$ Degussa $\mathrm{P} 25$ powders. Major peaks were observed at 3411, 1630 and $<1000 \mathrm{~cm}^{-1}$ (Fig. 3), which is similar to the results reported by Dolat et al. ${ }^{9}$. The band at $3411 \mathrm{~cm}^{-1}$ was attributed to $\mathrm{O}-\mathrm{H}$ stretching vibration, while the band at $1630 \mathrm{~cm}^{-1}$ area was ascribed to $\mathrm{O}-\mathrm{H}$ bending of water molecules absorbed onto the catalyst surface ${ }^{9,18}$. The bands at 460 and $694 \mathrm{~nm}$ were assigned to the stretching vibration of $\mathrm{Ti}-\mathrm{O}^{18}$. The spectra of $\mathrm{C}, \mathrm{N}-\mathrm{TiO}_{2}$ did not show additional peaks when compared to the spectra of unmodified $\mathrm{TiO}_{2}$. However, for the peak at $<1000 \mathrm{~cm}^{-1}$ the frequency was shifted from $694 \mathrm{~nm}$ for $\mathrm{TiO}_{2}$ to $460 \mathrm{~nm}$ for $\mathrm{C}, \mathrm{N}-\mathrm{TiO}_{2}$. This frequency movement to a lower wavelength for $\mathrm{C}, \mathrm{N}-\mathrm{TiO}_{2}$ was attributable to the interaction between the impregnated $\mathrm{C}$ and $\mathrm{N}^{9}$.

Comparison of photocatalytic activities between $\mathrm{C}, \mathrm{N}$ $\mathrm{TiO}_{2}$ and unmodified $\mathrm{TiO}_{2}$ systems: The photocatalytic activities of a $\mathrm{C}, \mathrm{N}-\mathrm{TiO}_{2}$ composite for cleaning of gaseous aromatic compounds (BTEX) were examined under a variety of operational conditions. Furthermore, the photocatalytic activities of commercial titania (Degussa P25 $\mathrm{TiO}_{2}$ ) were compared to those of the $\mathrm{C}, \mathrm{N}-\mathrm{TiO}_{2}$. Fig. 5 shows the average degradation efficiencies for all compounds determined using 


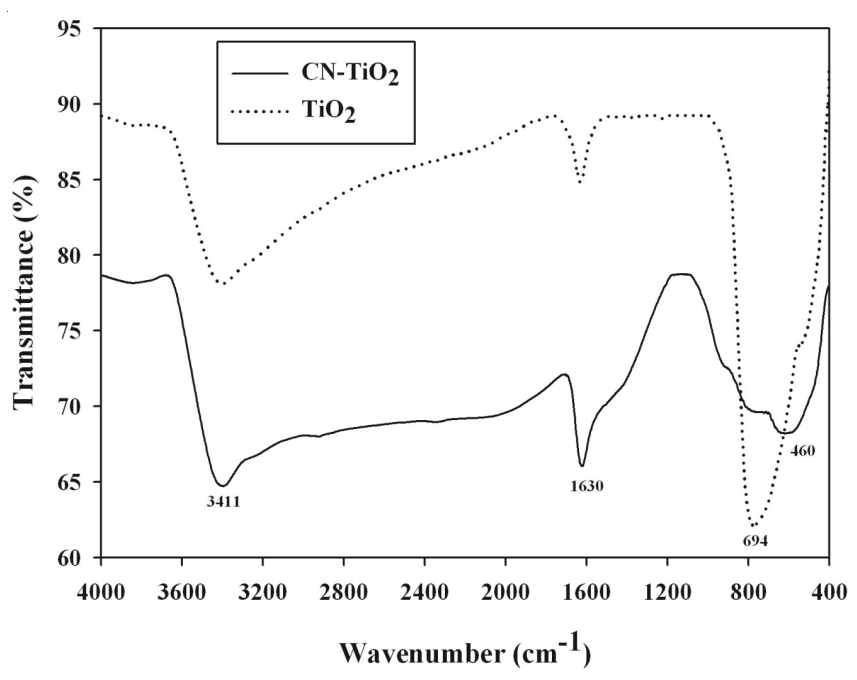

Fig. 4. Fourier transform infrared spectra of $\mathrm{C}, \mathrm{N}-\mathrm{TiO}_{2}$ and $\mathrm{TiO}_{2}$ powders

the $\mathrm{C}, \mathrm{N}-\mathrm{TiO}_{2}$ and commercial $\mathrm{TiO}_{2}$ under visible-light irradiation. The decomposition efficiencies obtained from the C,N$\mathrm{TiO}_{2}$ photocatalytic system were higher than those of the $\mathrm{TiO}_{2}$ system. The average photocatalytic degradation efficiencies for BTEX obtained from the $\mathrm{C}, \mathrm{N}-\mathrm{TiO}_{2}$ system were 27, 81, 95 and $99 \%$, respectively, whereas those of the $\mathrm{TiO}_{2}$ powders were close to zero, 19,47 and $56 \%$, respectively. These findings
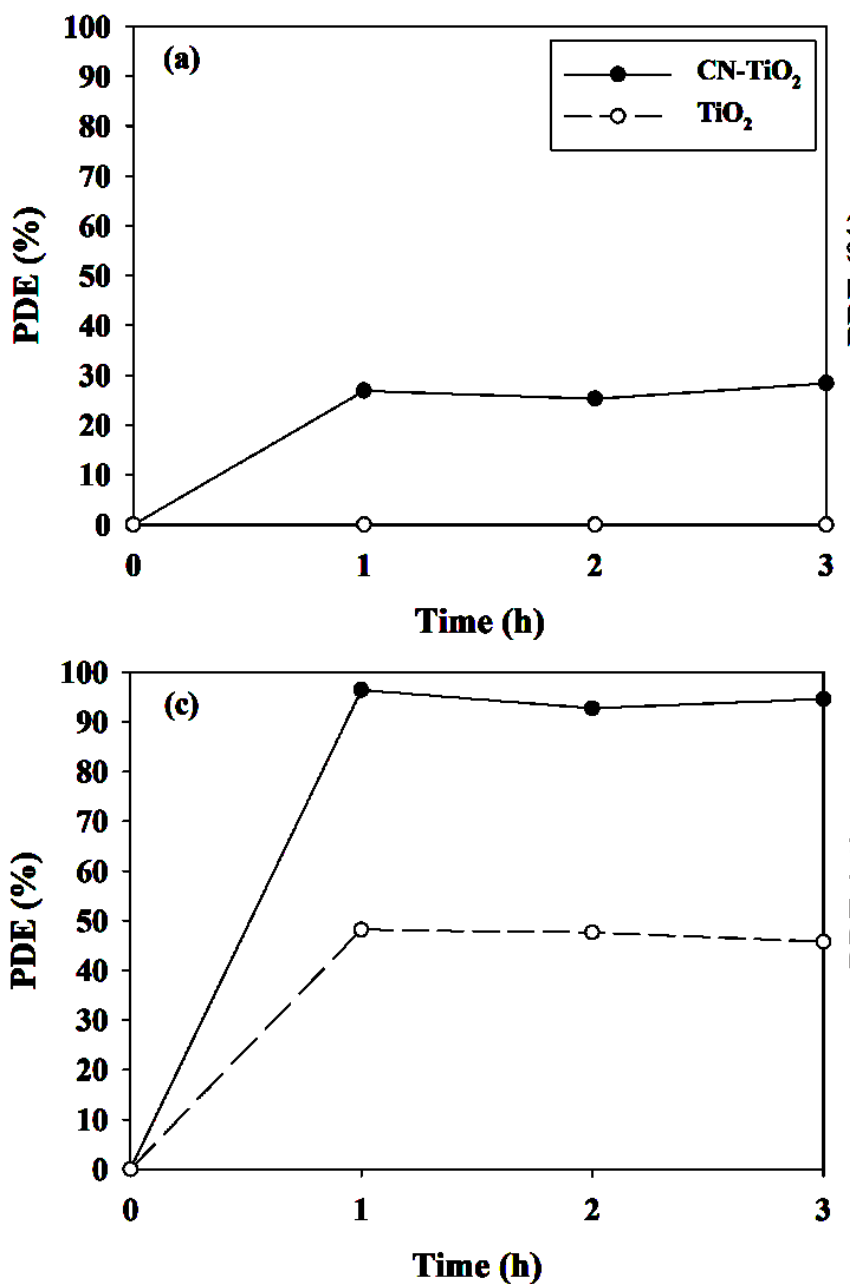

indicate that the $\mathrm{C}, \mathrm{N}-\mathrm{TiO}_{2}$ photocatalyst was superior for photocatalytic decomposition of toxic gas-phase aromatic pollutants to the reference Degussa $\mathrm{P} 25 \mathrm{TiO}_{2}$ photocatalyst under visible-light irradiation. In turn, this identification supports the assertion that $\mathrm{C}$ and $\mathrm{N}$ elements embedded into $\mathrm{TiO}_{2}$ networks could enhance the visible-light absorbance of $\mathrm{TiO}_{2}$ and therefore its photocatalytic activities. These findings are similar to those of other studies ${ }^{11,19,23}$, in which $\mathrm{C}, \mathrm{N}-\mathrm{TiO}_{2}$ exhibited enhanced photocatalytic activities for the degradation of water-based or inorganic gas pollutants. This enhanced photocatalytic activity of the $\mathrm{C}, \mathrm{N}-\mathrm{TiO}_{2}$ photocatalyst was ascribed to the combined effect of $\mathrm{C}$ and $\mathrm{N}$ atoms in the $\mathrm{TiO}_{2}$ networks. Previous studies ${ }^{11,19,23}$ suggested that $\mathrm{C}$ atoms could act as a photosensitizer, which transfers excited electron to surface-adsorbed oxygen molecules to form reactive $\mathrm{O}_{2}{ }^{-}$, thereby initiating the degradation of chemicals. Moreover, $\mathrm{N}$ atoms might produce low energy levels of $\mathrm{N} 2 \mathrm{p}$ and $\mathrm{O} 2 \mathrm{p}$ states or introduce a mid-gap (N 2p) energy level.

Photocatalytic decomposition efficiencies according to lamp type: The photocatalytic activities of a $\mathrm{C}, \mathrm{N}-\mathrm{TiO}_{2}$ photocatalyst were evaluated for degradation of BTEX using two different light sources (8-W fluorescent daylight lamp and violet visible light-emitting diodes). As shown in Fig. 6, the photocatalytic degradation efficiencies for BTEX were higher for the photocatalytic system with the fluorescent lamp than

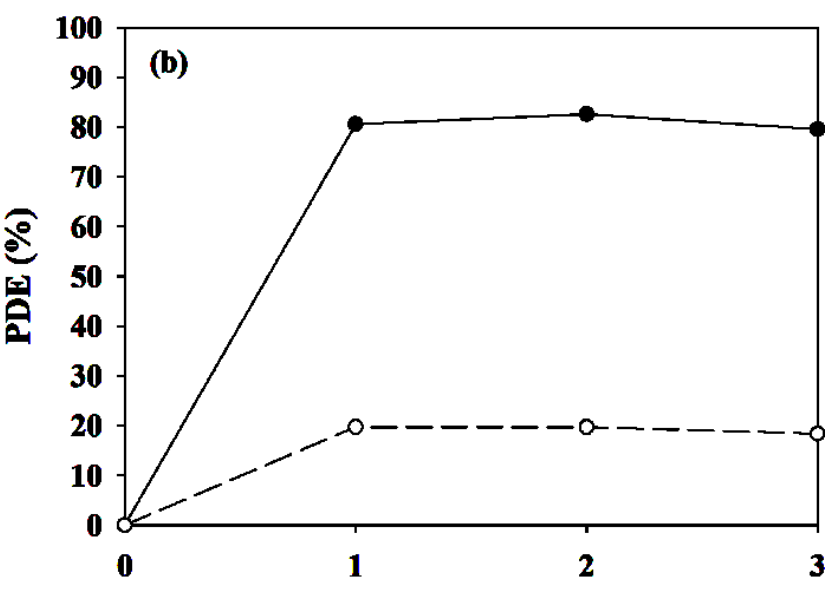

Time (h)

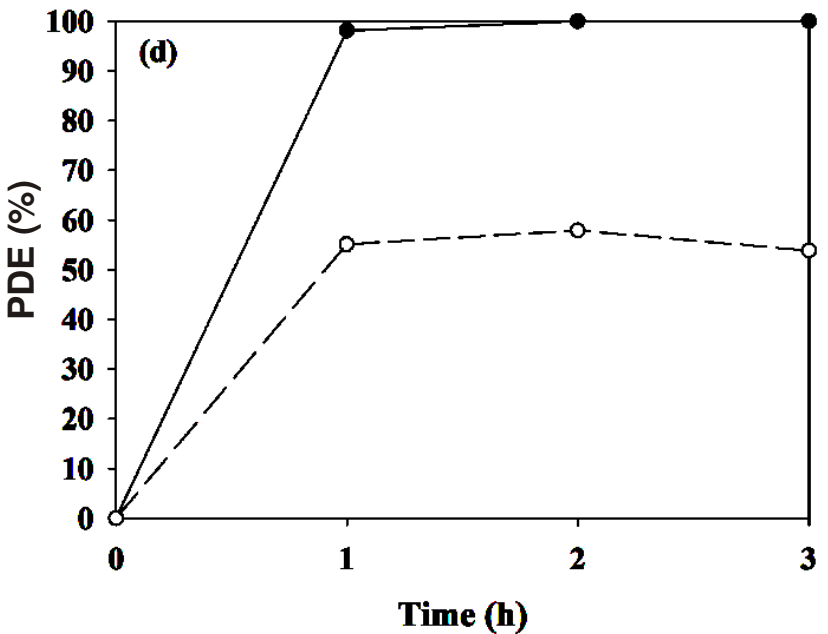

Fig. 5. Comparison of photocatalytic decomposition efficiencies (PDEs) of (a) benzene, (b) toluene, (c) ethyl benzene, and (d) $o$-xylene between $\mathrm{C}, \mathrm{N}-\mathrm{TiO}_{2}$ and unmodified $\mathrm{TiO}_{2}$ photocatalytic systems 

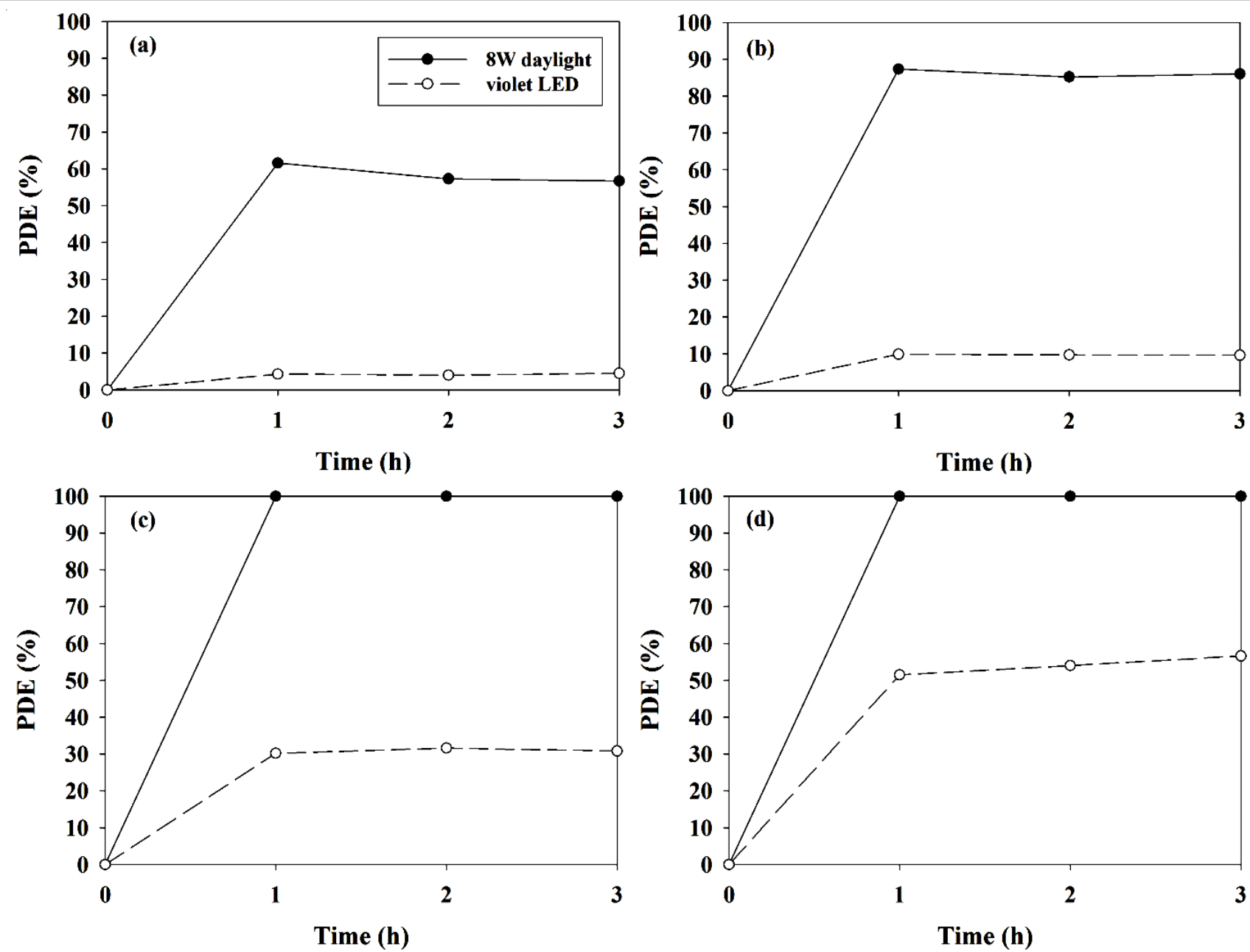

Fig. 6. Photocatalytic decomposition efficiencies (PDEs) of (a) benzene, (b) toluene, (c) ethyl benzene, and (d) o-xylene determined via a photocatalytic system with $\mathrm{C}, \mathrm{N}-\mathrm{TiO}_{2}$ and $\mathrm{TiO}_{2}$, according to lamp type

for that with light-emitting diodes. The average degradation efficiencies for BTEX obtained from the former system were 59 and $86 \%$, close to zero and close to zero, respectively, whereas those of the latter system were $4,10,31$ and $54 \%$, respectively. Photocatalytic degradation efficiency is proportional to light intensity ${ }^{24}$. The fluorescent lamp exhibited lower light intensity $\left(1.6 \mathrm{~mW} \mathrm{~cm}^{-2}\right)$ than that of the light-emitting diodes $\left(0.2 \mathrm{~mW} \mathrm{~cm}^{-2}\right)$, indicating that light intensity was an important factor for the difference in degradation efficiencies between the fluorescent lamp and light-emitting diodes under the experimental conditions used in the present study. Moreover, the light wavelength of fluorescent lamp was distributed at a wide range of 400-720 nm, which comprised lower wavelengths than that of the light-emitting diodes. Thus, the elevated degradation efficiency for the fluorescent lamp/C,N$\mathrm{TiO}_{2}$ system was attributed to higher light absorbance by $\mathrm{C}, \mathrm{N}-$ $\mathrm{TiO}_{2}$ powders at a low wavelength, as shown previously in the UV-visible spectra (Fig. 3). In addition, the power supplied by the fluorescent lamp was $8 \mathrm{~W}$, whereas it was $1.9 \mathrm{~W}$ for the light-emitting diodes, suggesting that a higher power supplied by the fluorescent lamp would also result in elevated removal efficiencies for BTEX. Other studies ${ }^{25,26}$ have also reported that a conventional 8-W fluorescent lamp exhibited higher photocatalytic activities for degradation of gaseous dimethyl sulfide or formaldehyde, but that light-emitting diodes could still be utilized as energy-efficient alternative light sources for the photocatalytic systems.

\section{Conclusion}

This work explored the photocatalytic activities of C,N$\mathrm{TiO}_{2}$ photocatalysts for the purification of indoor-level gaseous BTEX under different conditions. The surface characteristics of the as-prepared $\mathrm{C}, \mathrm{N}-\mathrm{TiO}_{2}$ photocatalysts differed from those of the Degussa $\mathrm{P} 25 \mathrm{TiO}_{2}$ photocatalyst. In particular, the $\mathrm{C}, \mathrm{N}-$ $\mathrm{TiO}_{2}$ powders exhibited a shift in the absorbance spectrum towards the visible light region when compared to $\mathrm{TiO}_{2}$ powders, indicating that the as-prepared $\mathrm{C}, \mathrm{N}-\mathrm{TiO}_{2}$ photocatalyst could be effectively activated by visible-light irradiation. Another major finding was that the $\mathrm{C}, \mathrm{N}-\mathrm{TiO}_{2}$ photocatalytic system showed superior BTEX decomposition efficiencies to unmodified $\mathrm{TiO}_{2}$ under visible-light irradiations. Moreover, the effects of the photocatalytic activity of $\mathrm{C}, \mathrm{N}-\mathrm{TiO}_{2}$ on the type of light sources were quantified.

\section{ACKNOWLEDGEMENTS}

This work was supported by the National Research Foundation of Korea (NRF) grant funded by the Korean Government (MEST) (No. 2011-0027916). 


\section{REFERENCES}

1. S. Yin, Y. Aita, M. Komatsu, J. Wang, Q. Tang and T. Sato, J. Mater. Chem., 15, 674 (2005)

2. H. Li, D. Wang, H. Fan, P. Wang, T. Jiang and T. Xie, J. Colloid Interf. Sci., 354, 175 (2011).

3. T. Lindgren, J.M. Mwabora, E. Avendaño, J. Jonsson, A. Hoel, C.-G. Granqvist and S.-E. Lindquist, J. Phys. Chem. B, 107, 5709 (2003).

4. R. Asahi, T. Morikawa, T. Ohwaki, K. Aoki and Y. Taga, Science, 293, 269 (2001).

5. D. Valentin, C. Pacchioni and A. Selloni, Chem. Matter., 17, 6656 (2005).

6. X. Chen and C. Burda, J. Am. Chem. Soc., 130, 5018 (2008).

7. R. Leary and A. Westwood, Carbon, 49, 741 (2011).

8. Y. Xie, Y. Li and X. Zhao, J. Mol. Catal. A, 277, 119 (2007).

9. D. Dolat, N. Quici, E. Kusiak-Nejman, A.W. Morawski and G. Li Puma, Appl. Catal. B, 115-116, 81 (2012).

10. X. Wang and T.-T. Lim, Appl. Catal. B, 100, 355 (2010).

11. S. Yin, M. Komatsu, Q. Zhang, F. Saito and T. Sato, J. Mater. Sci., 42, 2399 (2007)

12. S. Zhang and L. Song, Catal. Comm., 10, 1725 (2009).
13. D. Chen, Z. Jiang, J. Geng, Q. Wang and D. Yang, Ind. Eng. Chem. Res., 46, 2741 (2007).

14. A. Fujishima, X. Zhang and D.A. Tryk, Surf. Sci. Rep., 63, 515 (2008).

15. T. Ohura, T. Amagai, X. Shen, S. Li, P. Zhang and L. Zhu, Atmos. Environ., 43, 6352 (2009).

16. C.S. Chen, Y.C. Hseu, S.H. Liang, J.-Y. Kuo and S.C. Chen, J. Hazard. Mater, 153, 351 (2008).

17. W.K. Jo and J.T. Kim, J. Hazard. Mater, 164, 360 (2009).

18. S.H. Nam, T.K. Kim and J.H. Boo, Catal. Today, 185, 259 (2012).

19. C. Yu and J. Yu, Catal. Lett., 129, 462 (2009).

20. T. Horikawa, M. Katoh and T. Tomida, Micropor. Mesopor. Mater., 110, 397 (2008).

21. H. Znad and Y. Kawase, J. Mol. Catal. A, 314, 55 (2009).

22. K.R. Wu and C.H. Hung, Appl. Surf. Sci., 256, 1595 (2009).

23. X. Yang, C. Cao, L. Erickson, K. Hohn, R. Maghirang and K. Klabunde, J. Catal., 260, 128 (2008).

24. T.H. Lim and S.D. Kim, Chemosphere, 54, 305 (2004).

25. J.L. Shie, C.H. Lee, C.S. Chiou, C.T. Chang, C.C. Chang and C.Y. Chang, J. Hazard. Mater., 155, 164 (2008).

26. W.K. Jo, S.S. Eun and S.H. Shin, Photochem. Photobiol., 87, 1016 (2011). 